\title{
Infection, Dissemination, and Transmission Potential of North American Culex quinquefasciatus, Culex tarsalis, and Culicoides sonorensis for Oropouche Virus
}

\author{
Bethany L. McGregor ${ }^{1} \mathbb{D}$, C. Roxanne Connelly ${ }^{2}$ and Joan L. Kenney ${ }^{2, *(\mathbb{D})}$ \\ 1 Center for Grain and Animal Health Research, Agricultural Research Service, United States Department of \\ Agriculture, Manhattan, KS 66502, USA; Bethany.McGregor@usda.gov \\ 2 Arboviral Diseases Branch, Division of Vector-Borne Diseases, Centers for Disease Control and Prevention, \\ Fort Collins, CO 80521, USA; csz5@cdc.gov \\ * Correspondence: vwx1@cdc.gov; Tel.: +1-970-221-6465
}

Citation: McGregor, B.L.;

Connelly, C.R.; Kenney, J.L. Infection,

Dissemination, and Transmission

Potential of North American Culex quinquefasciatus, Culex tarsalis, and Culicoides sonorensis for Oropouche Virus. Viruses 2021, 13, 226. https:// doi.org/10.3390/v13020226

Academic Editors: Esther Schnettler and Benjamin Brennan

Received: 15 January 2021

Accepted: 30 January 2021

Published: 2 February 202

Publisher's Note: MDPI stays neutral with regard to jurisdictional claims in published maps and institutional affiliations.

Copyright: (c) 2021 by the authors. Licensee MDPI, Basel, Switzerland. This article is an open access article distributed under the terms and conditions of the Creative Commons Attribution (CC BY) license (https:// creativecommons.org/licenses/by/ $4.0 /)$.

\begin{abstract}
Oropouche virus (OROV), a vector-borne Orthobunyavirus circulating in South and Central America, causes a febrile illness with high rates of morbidity but with no documented fatalities. Oropouche virus is transmitted by numerous vectors, including multiple genera of mosquitoes and Culicoides biting midges in South America. This study investigated the vector competence of three North American vectors, Culex tarsalis, Culex quinquefasciatus, and Culicoides sonorensis, for OROV. Cohorts of each species were fed an infectious blood meal containing $6.5 \log _{10} \mathrm{PFU} / \mathrm{mL}$ OROV and incubated for 10 or 14 days. Culex tarsalis demonstrated infection (3.13\%) but not dissemination or transmission potential at 10 days post infection (DPI). At 10 and 14 DPI, Cx. quinquefasciatus demonstrated $9.71 \%$ and $19.3 \%$ infection, $2.91 \%$ and $1.23 \%$ dissemination, and $0.97 \%$ and $0.82 \%$ transmission potential, respectively. Culicoides sonorensis demonstrated $86.63 \%$ infection, $83.14 \%$ dissemination, and $19.77 \%$ transmission potential at 14 DPI. Based on these data, $C x$. tarsalis is unlikely to be a competent vector for OROV. Culex quinquefasciatus demonstrated infection, dissemination, and transmission potential, although at relatively low rates. Culicoides sonorensis demonstrated high infection and dissemination but may have a salivary gland barrier to the virus. These data have implications for the spread of OROV in the event of a North American introduction.
\end{abstract}

Keywords: vector borne diseases; arboviruses; insect vectors; Bunyaviridae infections; Culicidae; Ceratopogonidae

\section{Introduction}

Oropouche virus (OROV; Bunyavirales; Peribunyaviridae; Orthobunyavirus) is the causative agent of Oropouche fever, a febrile illness that occurs throughout South and Central America. Since its initial isolation in 1955 from a febrile patient in Trinidad and Tobago, OROV is likely to have affected more than half a million people [1]. Multiple large-scale outbreaks in countries like Brazil [2,3], Panama [4], and Peru [5] have been documented, as well as additional human cases and detections in sylvatic reservoir hosts throughout South America [6,7]. Currently, OROV infection is known to result in high levels of morbidity, however human fatalities are unknown from this virus [8]. The symptoms of OROV often closely resemble those of other febrile illnesses such as dengue and Zika. Therefore, it is likely that some cases of OROV have been previously misdiagnosed and this virus is more widespread than previously thought [4].

Oropouche virus transmission is maintained in two cycles. The first, an urban cycle, is maintained primarily by the biting midge Culicoides paraensis Goeldi and the mosquito Culex quinquefasciatus Say through humans [9]. The other is a highly complex sylvatic cycle involving numerous arthropod species, including Aedes serratus (Theobald), Cx. quinquefasciatus, Coquillettidia venezuelensis (Theobald), and Culicoides, transmitting the virus amongst a variety of reservoir hosts, including birds, sloths, primates, and rodents [2,8]. Due to the 
great diversity of hosts and vectors associated with sylvatic transmission, it is likely that vectors and reservoirs in North America could be susceptible to OROV in an introduction event. North America is also home to numerous avian families that have susceptible South American members, such as the Tyrannidae (tyrant flycatchers), Troglodytidae (wrens), Fringillidae (finches), and Thraupidae (tanagers) [8,10]. Migration patterns of birds moving between North and South America could contribute to the potential movement and introduction of OROV, a phenomenon that has been speculated with the mosquito-borne West Nile virus [11] and with ticks carrying spotted fever Rickettsia agents and Lyme disease [12,13]. Flyway-mediated movement has also been proposed as one mechanism by which Eastern equine encephalitis has moved both within the United States [14] as well as into the United States from South America [15]

The lack of data on how OROV could establish and be transmitted in North America is concerning in light of other recent arboviral introduction events. Zika virus, which had been known for decades, presented with new, concerning symptoms in 2016 and created a public health crisis as the pathogen spread in southern Florida [16]. During 2005-2006, a single amino acid mutation in the Chikungunya virus genome led to a significant change in vector specificity leading to a major outbreak on Reunion island [17]. While OROV is not currently known to result in fatalities, orthobunyaviruses are known to undergo mutations at high rates leading to the evolution of new viral strains and sometimes completely novel viruses [18]. Recombination and reassortment of OROV with other orthobunyaviruses could also be a concern. Reassortment of OROV has already led to the establishment of numerous novel viruses including Madre de Dios and Iquitos viruses in South America [18,19]. Numerous orthobunyaviruses with human pathogenicity occur in North America, including Cache Valley virus, Jamestown Canyon virus, and La Crosse virus, which is concerning from a recombination perspective.

Vector control is often regarded as the primary method for controlling vector-borne disease outbreaks [20]. Increasing incursions of vector-borne diseases within the United States highlight our lack of preparedness for large-scale control of many vector species [21,22]. Furthermore, control strategies have not been developed for many North American Culicoides species, with most evaluations that have been conducted occurring in agricultural settings [23]. In the event of a North American OROV outbreak transmitted by a Culicoides species, there is currently no established large-scale control protocol for members of this genus. For these reasons, it is imperative that we gain a better understanding of the potential ecology of this pathogen prior to an introduction into North America. The present study investigated the vector competence of colony specimens of three common North American vector species including Culex tarsalis Coquillett, Cx. quinquefasciatus, and Culicoides sonorensis Wirth \& Jones.

\section{Materials and Methods}

\subsection{Insects}

Two mosquito colonies were used for this experiment: Culex tarsalis, from the Bakersfield colony originally colonized from Bakersfield, CA, in 1952, and Culex quinquefasciatus, from the Sebring colony originally colonized from a population in Florida in 1988. Neither colony is outcrossed with wild members. Both $C x$. tarsalis and $C x$. quinquefasciatus were reared in the Centers for Disease Control and Prevention clean insectary in an incubator (Thermo Scientific, Thermo Fisher Scientific, Waltham, MA, USA) held at $27.5{ }^{\circ} \mathrm{C}$ on a 12:12 L/D schedule. Culicoides sonorensis individuals (from the Ausman colony established from a population collected in Brighton, CO, in 2001 that is not outcrossed with wild individuals) were received from the United States Department of Agriculture ArthropodBorne Animal Diseases Research Unit (USDA ABADRU) as 1-day-old adults and held in incubators in the CDC clean insectary under the same conditions as mosquitoes. Adult mosquitoes and midges were provided with $10 \%$ sucrose solution ad libitum until infection. The day prior to infection, groups of $\leq 50$ individuals for all three species were moved into $475 \mathrm{~mL}$ paper cups with double layered mesh on top. Cups of midges and mosquitoes 
were moved into the BSL-3 incubators for a 1-day acclimation period at $28{ }^{\circ} \mathrm{C}$ prior to blood-feeding. All adult mosquitoes and midges were between 3-7 days old for infections.

\subsection{Infection}

Midges and mosquitoes were fed $6.5 \log _{10}$ plaque forming units (PFU)/mL of Oropouche virus. The viral strain used was derived from a 1955 viral isolate from a febrile patient in Trinidad and Tobago obtained from the CDC Arbovirus Reference Collection. The virus had a history of five passages in an unknown media, five passages in suckling mice, and one passage in Vero cells. The stock was passaged two additional times on Vero cells to a titer of $8 \log$ PFU/mL prior to use in infectious blood meals. Virus in growth medium was diluted in defibrinated goose blood (Colorado Serum Company, Denver, CO, USA) for both Culex species and defibrinated calf blood (Colorado Serum Company) for Culicoides. Infectious blood meals were provided using a Hemotek blood feeding system (Hemotek Ltd., Blackburn, UK) with a Parafilm membrane for all species. Insects were provided access to blood heated to $37^{\circ} \mathrm{C}$ in an incubator set at $28^{\circ} \mathrm{C}$ for one hour prior to sorting. After blood feeding, mosquitoes were processed by exposing cups to $-20^{\circ} \mathrm{C}$ for $40 \mathrm{~s}$ and then sorting blood-fed mosquitoes in a petri dish on ice. Because midges could not be knocked down with cold due to susceptibility to water droplets, Culicoides were knocked down and sorted using a $\mathrm{CO}_{2}$ fly staging pad (Item \#BGSU-12, Lab Scientific, Danvers, MA, USA). All blood engorged insects were placed into clean $475 \mathrm{~mL}$ paper cups in groups of $\leq 50$ individuals and provided $10 \%$ sucrose solution ad libitum until collection at 10 or 14 days post infection (DPI). Additionally, a subset of individuals was fed clean blood without the addition of virus as controls for each cohort. The control individuals were exposed to the same knockdown and experimental conditions as the virus-fed individuals.

\subsection{Collections}

Insects were scheduled for dissection and saliva collection at 14 DPI. Poor survival by $C x$. tarsalis individuals necessitated termination of their incubation period at $10 \mathrm{DPI}$. For this reason, a subset of $C x$. quinquefasciatus were also collected at 10 DPI for a direct comparison with $C x$. tarsalis. All $C$. sonorensis and the remaining $C x$. quinquefasciatus were collected at 14 DPI. For each insect, legs and wings were collected into microcentrifuge tubes containing Dulbecco's Modified Eagle Medium (Gibco, ThermoFisher Scientific, Waltham, MA) supplemented with 10\% fetal bovine serum (Omega Scientific, Inc., Tarzana, CA, USA), 4\% penicillin streptomycin (Gibco, Thermo Fisher Scientific), and 1\% amphotericin b (Gibco, Thermo Fisher Scientific) $(500 \mu \mathrm{L}$ for mosquitoes, $300 \mu \mathrm{L}$ for midges) with four $2 \mathrm{~mm}$ zirconium oxide beads (Glen Mills Inc., Clifton, NJ, USA). Saliva was collected by inserting the insect's mouthparts into a $5 \mu \mathrm{L}$ capacity capillary tube (Drummond Scientific, Broomall, PA, USA) partially filled with immersion oil to facilitate uptake of saliva [24]. Both midges and mosquitoes were allowed to salivate for one hour prior to collecting capillary tubes into supplemented media without beads $(300 \mu \mathrm{L}$ for mosquitoes, $100 \mu \mathrm{L}$ for midges) and collecting bodies into a separate tube containing supplemented media (500 $\mu \mathrm{L}$ for mosquitoes, $300 \mu \mathrm{L}$ for midges) and four $2 \mathrm{~mm}$ zirconium oxide beads.

\subsection{Sample Testing}

All samples were tested by plaque assay on Vero cells (African green monkey kidney cells). Body samples were tested first to investigate whether the virus was able to successfully infect midgut tissues and establish a midgut infection $[25,26]$. For those individuals showing positive body samples, legs were then tested to determine whether virus was able to escape the midgut and disseminate throughout the insect's body. Finally, for those showing a disseminated infection in body tissues, saliva was then tested to determine whether the virus was able to infect the salivary glands and be transmitted in saliva. Body and leg samples were homogenized with a tissue lyser at $20 \mathrm{~Hz}$ for $6 \mathrm{~min}$ (Qiagen, Hilden, Germany) followed by centrifugation at 10,500 RPM for 5 min (Eppendorf, Hamburg, Germany). Saliva samples were centrifuged at 10,500 RPM for 5 min to extract all saliva from capillary tubes prior to plating. Serial dilutions in complete media were used to titrate 
samples as necessary. Due to the extremely small volume of saliva produced by Culicoides, samples that did not produce positive results by plaque assay were further tested by cytopathic effects assays in order to identify any virus positive saliva samples. Cytopathic effects assays were conducted by pipetting $50 \mu \mathrm{L}$ of the sample and $50 \mu \mathrm{L}$ complete media onto monolayers of Vero cells in 6-well plates. The plates were then rocked every $15 \mathrm{~min}$ for $1 \mathrm{~h}$ to facilitate viral entry into cells. An additional $2 \mathrm{~mL}$ complete media was then added to each well and plates were observed for up to 2 weeks for cytopathic effects.

\subsection{Data Analysis}

Infection, dissemination, and transmission rates were calculated for each species and time point studied. Infection rates were calculated as the number of positive bodies divided by the total number of individuals assayed. Dissemination rates were calculated as the total number of positive legs divided by the total number with positive bodies. Transmission potential rates were calculated as the total number of positive saliva samples divided by the total number with positive body samples. Overall infection, dissemination, and transmission potential rates were also calculated by dividing the number with positive bodies, legs, and saliva, respectively, by the total number that took an infectious blood meal for each cohort.

When adequate data were available, titers were evaluated for normality through data visualization and Shapiro-Wilk tests. The titer data were determined to be non-normally distributed (Shapiro-Wilk $p<0.001$ ), so titers were directly compared through MannWhitney U tests. Fisher's exact tests using Bonferroni corrections were then used to evaluate whether rates of infection, dissemination, and transmission potential were significantly different between study species and between 10 and 14 DPI results for $C x$. quinquefasciatus. Finally, Mann-Whitney U tests were run to determine whether mortality observed in experimental cohorts was significantly different from control cohorts. All statistics were run using the stats package in $\mathrm{R}$ statistical computing software (R Core Team, Vienna, Austria) [27].

\section{Results}

\subsection{Infection, Dissemination, and Transmission Potential}

All $C x$. tarsalis and a subset of $C x$. quinquefasciatus were sampled on 10 DPI due to poor survival of $C x$. tarsalis individuals. For $C x$. tarsalis, 3 out of 96 individuals (3.13\%; Supplementary File S1) had detectable virus in body samples (Table 1). The average viral titer for $C x$. tarsalis bodies $(n=3)$ was $31.13 \mathrm{PFU} / \mathrm{mL}$ (Figure 1). There were no positive leg or saliva samples for $C x$. tarsalis.

Table 1. Overall rates of infection, dissemination, and transmission potential for Culex tarsalis and Culex quinquefasciatus at 10 days post infection and Culex quinquefasciatus and Culicoides sonorensis at 14 days post infection. Numbers in parentheses represent the percentage of individuals out of the total sample size tested.

\begin{tabular}{|c|c|c|c|c|c|}
\hline DPI & Species & $\mathbf{N}$ & Infection & Dissemination & Transmission \\
\hline \multirow[t]{2}{*}{10} & Culex tarsalis & 96 & $\begin{array}{c}3 \\
(3.13)\end{array}$ & $\begin{array}{c}0 \\
(0)\end{array}$ & $\begin{array}{c}0 \\
(0)\end{array}$ \\
\hline & Culex quinquefasciatus & 103 & $\begin{array}{c}10 \\
(9.71)\end{array}$ & $\begin{array}{c}3 \\
(2.91) \\
\end{array}$ & $\begin{array}{c}1 \\
(0.97) \\
\end{array}$ \\
\hline \multirow[t]{2}{*}{14} & Culex quinquefasciatus & 244 & $\begin{array}{c}47 \\
(19.3)\end{array}$ & $\begin{array}{c}3 \\
(1.23)\end{array}$ & $\begin{array}{c}2 \\
(0.82)\end{array}$ \\
\hline & Culicoides sonorensis & 172 & $\begin{array}{c}149 \\
(86.63)\end{array}$ & $\begin{array}{c}143 \\
(83.14)\end{array}$ & $\begin{array}{c}34 \\
(19.77)\end{array}$ \\
\hline
\end{tabular}




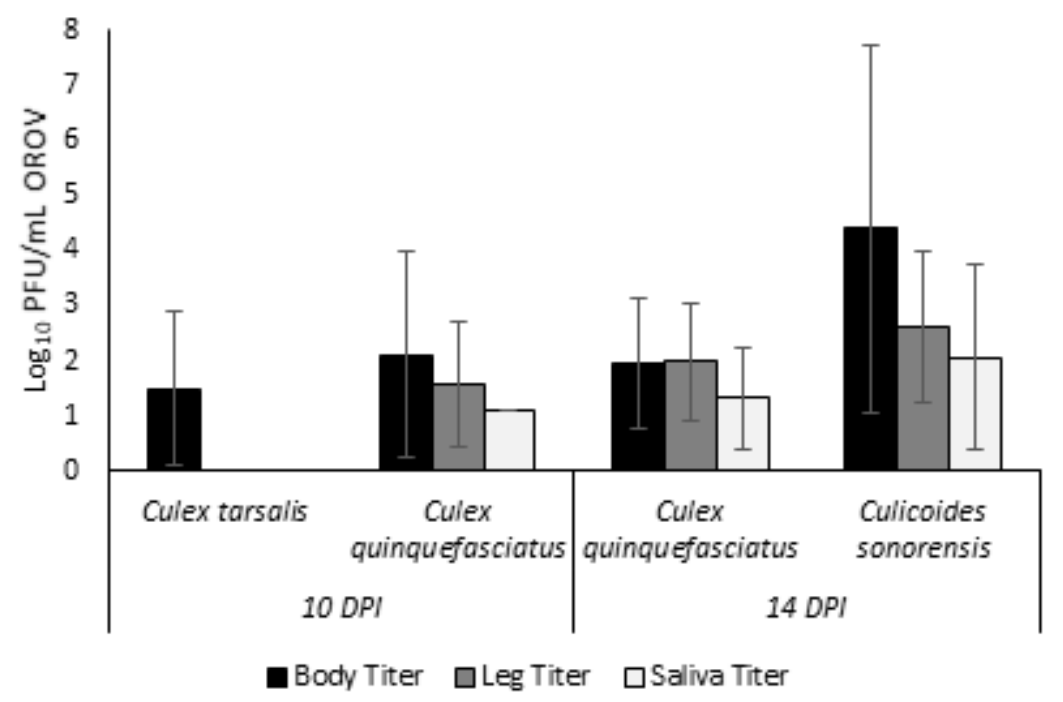

Figure 1. Viral OROV titers present in bodies, legs, and saliva of Culex tarsalis and Culex quinquefasciatus at 10 days post infection and Culex quinquefasciatus and Culicoides sonorensis at 14 days post infection. Titers are depicted as log plaque forming units per $\mathrm{mL}$.

For the cohort of $C x$. quinquefasciatus sampled at 10 DPI, 10 out of 103 individuals $(9.71 \%$, Table 1) had positive bodies at an average viral titer of $127.72 \mathrm{PFU} / \mathrm{mL}$ (Figure 1). Of the $10 C x$. quinquefasciatus with positive body samples, three (30\%) showed evidence of a disseminated infection through positive plaque assays of leg tissues at an average viral titer of $36.65 \mathrm{PFU} / \mathrm{mL}$. Finally, one individual $(30 \%)$ had a positive salivary sample indicating transmission potential. However, the viral titer of this one sample was just 13.33 PFU/mL, likely a salivary titer too low for transmission to occur.

The remaining $C x$. quinquefasciatus were sampled at 14 DPI. Out of 244 individuals assayed, 47 had positive body samples (19.3\%, Table 1) with an average viral titer of $87.84 \mathrm{PFU} / \mathrm{mL}$ (Figure 1). Dissemination was observed for three of these 47 individuals $(6.38 \%)$ with an average viral titer of $100 \mathrm{PFU} / \mathrm{mL}$. Finally, two of these individuals $(4.26 \%)$ with a disseminated infection further showed a transmissible infection with presence of virus in saliva samples. The average salivary titer for $C x$. quinquefasciatus at $14 \mathrm{DPI}$ was $21.67 \mathrm{PFU} / \mathrm{mL}$.

All C. sonorensis individuals were collected at 14 DPI. Out of 172 total individuals assayed, 149 developed body infections $(86.63 \%$, Table 1$)$ with an average viral titer of $2.5 \times 10^{4} \mathrm{PFU} / \mathrm{mL}$ (Figure 1). Dissemination was observed in 143 of these individuals $(95.97 \%)$ with an average leg titer of $404 \mathrm{PFU} / \mathrm{mL}$. Saliva was assayed both through plaque assays and cytopathic effects assays. By plaque assay, 24 positive saliva samples were identified at an average salivary titer of $115.42 \mathrm{PFU} / \mathrm{mL}$. Cytopathic effect assays identified an additional 10 positive samples bringing the total transmission potential rate to 34 of 149 individuals (22.82\%).

\subsection{Statistical Analyses of Viral Titers and Infections between Vectors}

Due to the difference in incubation time, the $C x$. tarsalis could only statistically be compared with the 10 DPI $C x$. quinquefasciatus. While the average viral titers for $C x$. quinquefasciatus bodies were higher than that of $C x$. tarsalis, Mann-Whitney $\mathrm{U}$ tests determined this was not significant $(\mathrm{W}=11, p=0.54)$. No further statistical analyses of titer were completed for this pairing as no $C x$. tarsalis displayed any dissemination or transmission potential. Infection rates for $C x$. quinquefasciatus were higher than for $C x$. tarsalis, although this was not significant (Fisher's exact $p=0.08$ ).

For the 14 DPI comparison between $C x$. quinquefasciatus and $C$. sonorensis, $C$. sonorensis had a significantly higher viral titer in bodies $(\mathrm{W}=183, p<0.001)$ and legs $(\mathrm{W}=51.5$, $p=0.03)$, but not in saliva ( $\mathrm{W}=21.5, p=0.84)$. Furthermore, in Fisher's exact tests, the 
rates of infection $(p<0.001)$ and dissemination $(p<0.001)$ were significantly higher in $C$. sonorensis. Transmission potential was not significantly higher (Fisher's exact $p=0.15$ ) in $C$. sonorensis than in $C x$. quinquefasciatus.

Analyses were conducted to investigate whether the rates of infection and dissemination as well as viral titers varied significantly between 10 and 14 DPI in Culex quinquefasciatus. Significantly more $C x$. quinquefasciatus were infected on 14 DPI than 10 DPI ( $p=0.03)$, although no significant difference was observed in dissemination rates $(p=0.07)$. There was no significant difference in viral titers between 10 DPI and 14 DPI in bodies (W $=224.5$, $p=0.83$ ) or legs $(\mathrm{W}=0, p=0.08)$. Low transmission potential overall for $C x$. quinquefasciatus prevented further analysis of saliva results.

\subsection{Survival Rates of Experimental and Control Insects}

A subset of individuals from each cohort were fed clean blood without the addition of virus as controls. For $C x$. tarsalis, 7/11 unfed controls (63\%) survived until 10 DPI. Experimental $C x$. tarsalis experienced $41.2 \%$ survival through 10 DPI (96/233 individuals). While the survival of the experimental $C x$. tarsalis was low, this was not significantly different from the controls (Fisher's exact $p=0.21$ ). All of the $C x$. quinquefasciatus controls survived through days 10 and 14 (25/25 individuals, 100\%). Experimental $C x$. quinquefasciatus experienced $92 \%$ survival through 10 DPI $(103 / 112)$ which was not significantly different from controls (Fisher's exact $p=0.21$ ). The experimental $C x$. quinquefasciatus maintained through 14 DPI experienced $74.9 \%$ survival (244/326 individuals), which was significantly lower than the control survival (Fisher's exact $p=0.002$ ). There were $13 \mathrm{C}$. sonorensis maintained as controls, with $7(50 \%)$ surviving through 14 DPI. Out of 308 experimental C. sonorensis, 172 survived through the 14-day incubation period (55.8\%), which was not significantly different from the control survival (Fisher's exact $p=1$ ).

\section{Discussion}

Numerous arthropod vectors have been implicated in the spread of Oropouche virus in South and Central America. The present study investigated the vector potential for North American populations of common vector species. Both Culex species show very limited potential as competent vectors for OROV. Culex tarsalis, a common species throughout the western United States and present in parts of southern Canada and northern Mexico [28,29], was an inefficient vector, only sustaining infection but not dissemination or transmission potential of OROV. Culex quinquefasciatus, a confirmed South American vector whose range extends north into the southern United States [28,29], showed very limited vector potential but was able to achieve infection, dissemination, and transmission potential for some individuals. Culicoides sonorensis is a species with a large North American range including most of the United States west of the Mississippi river as well as parts of the southeastern United States, the southern portion of the Canadian provinces of British Columbia, Alberta, and Ontario, and in numerous states of Mexico as far south as Guerrero [30-32]. This species is a confirmed vector of a variety of animal pathogens such as bluetongue virus [33], epizootic hemorrhagic disease virus [34], Schmallenberg virus [35], vesicular stomatitis virus [36], and African horse sickness virus [37]. Based on the results of the present study, we can confirm that this wide-ranging species is also a competent vector of a human pathogen and was found to have the highest vector competence for OROV of the three species tested. This species sustained high levels of infection and dissemination and moderate levels of transmission potential.

The levels of infection, dissemination, and transmission potential observed inform us on the barriers to transmission that may be active in each species. Four barriers to transmission are typically acknowledged with mosquito infection, namely the midgut infection barrier, midgut escape barrier, salivary gland infection barrier, and salivary gland escape barrier [38]. Culex tarsalis, with low infection and no dissemination or transmission potential, likely has a barrier to midgut infection preventing the virus from establishing. For those few individuals where an infection was established, a midgut escape barrier likely 
prevented any further movement of the virus out of the midgut. For $C x$. quinquefasciatus, low infection and dissemination rates at both 10 and 14 DPI indicate that there are likely midgut infection and escape barriers active in this species as well. It is difficult to determine whether a salivary gland infection barrier is active in either of these Culex species due to the low number of individuals with disseminated infections. At 14 DPI, 2/3 individuals had virus positive saliva which may indicate a low-level salivary gland infection and escape barrier in $C x$. quinquefasciatus. Finally, $C$. sonorensis seems to lack a midgut infection and escape barrier with high infection and dissemination rates. However, the relatively low transmission potential identified with this species suggests the presence of a salivary gland infection and escape barrier. While we can make inferences about the presence of these barriers based on the infection, dissemination, and transmission potential rates, the specific barriers were not further investigated and require additional research.

The low transmission potential identified in $C$. sonorensis could also be attributable to difficulties in collecting adequate saliva for the detection of virus from members of this genus [39]. One previous study identified that numerous false negatives were generated from both capillary assays and honey card salivary assays conducted with $C$. sonorensis infected with epizootic hemorrhagic disease virus [40]. It is therefore possible that by only collecting saliva using capillary assays, we are missing a proportion of the transmission competent individuals with our assays [41,42]. Challenges to collecting saliva have been bypassed in other studies by testing full heads and using those data as a surrogate for transmission potential [36]. For our purposes of not only determining vector competence but identifying which barriers to transmission were active, it was imperative to collect saliva to determine whether virus was able to bypass the salivary gland infection and escape barriers.

In the present study, Culex quinquefasciatus showed relatively low rates of infection and dissemination, indicating that this species may not be an efficient vector of OROV. These data agree with previously conducted experiments finding low transmission potential of South American populations of this species in laboratory infection studies [43,44]. In fact, there is evidence that extraordinarily high viral titers of $\geq 9.5 \log _{10} \mathrm{SMLD}_{50} / \mathrm{mL}$ are needed to infect South American Cx. quinquefasciatus in the laboratory [44]. Culex quinquefasciatus is still often cited as a likely urban vector of OROV, although not as significant as Culicoides paraensis [45]. Minimum infection rates of OROV in $C x$. quinquefasciatus collected during an outbreak of febrile illness in Brazil indicated that 2.3 out of every 1000 specimens was likely to be infected [46]. It is possible that the low competence of this species is overcome by the extremely high abundance often seen in urban and suburban areas [47]. Vectorial capacity is a measure of the ability of a species to transmit a pathogen that takes into consideration both intrinsic characteristics like vector competence and extrinsic incubation period as well as extrinsic factors such as vector density, host use, and survival [48]. Based on this equation, the greater density of a vector can balance out a lower vector competence, meaning that even though $C x$. quinquefasciatus has low vector competence, it could still act as a significant viral vector due to abundance.

It is unclear whether infection rates for $C x$. tarsalis would increase if given an additional four days of incubation. Experimentally infected $C x$. tarsalis individuals in the present study experienced very poor survival compared to control individuals, although this effect was not significant. This may indicate a deleterious effect of OROV on $C x$. tarsalis, a phenomenon that, while uncommon, has been observed in other mosquitoborne pathogens [49]. For $C x$. quinquefasciatus which, at 14 DPI, did experience significantly more mortality than controls, we also have to wonder whether some individuals succumbed to the virus. It is also possible that this mortality resulted from the high titer of virus provided to these mosquitoes and with a lower titer, mortality rates may have been lower. Individuals that died prior to the 10- or 14-day incubation period were not tested for virus to determine whether they had developed an infection that may have led to mortality. Testing those insects could have provided some clarity on whether the viral infection was to blame for the mortality seen and should be considered in future studies 
where high mortality in experimental cohorts is observed. Regardless, while it is possible that higher $C x$. tarsalis infection rates would have been seen with increased survival and additional incubation time associated with a lower titer infection, a comparative cohort of $C x$. quinquefasciatus displayed higher infection as well as dissemination and transmission potential already occurring at $10 \mathrm{DPI}$ fed the same high infectious titer of OROV.

The viral titer of $6.5 \log _{10} \mathrm{PFU} / \mathrm{mL}$ used in this study is high, but we believe it is a relevant viral titer for this initial investigation. There are very little data on the circulating OROV viremia reached by non-human hosts in the sylvatic cycle. Most field studies do not collect wild vertebrates with circulating virus and, instead, investigate antibody prevalence. However, in experimentally infected mice, there is evidence that peak viral load in the plasma reaches $10^{6.0} \mathrm{TCID}_{50} / \mathrm{mL}$ [1]. In humans, titers were found to be between 4.5 and $5.7 \log _{10} \mathrm{PFU} / 0.1 \mathrm{~mL}$ in one outbreak [10] and viremia up to $7.3 \log _{10} \mathrm{SMLD}_{50}$ was recorded for one patient in another study [50]. Titers are highest during the first two days of illness followed by a decrease of one log on day three and a significant decline in following days [2], indicating that transmissible viremia probably does not last long in most patients. In one study conducted with the South American vector Culicoides paraensis, midges were successfully infected when feeding on human blood collected within the first two days of illness representing titers of $\geq 5.3 \log _{10} \mathrm{SMLD}_{50}$ [50]. Circulating titers of $\leq 5.2$ were inadequate to orally infect $C$. paraensis. Based on this information, the present infectious titer given of $6.5 \log _{10} \mathrm{PFU} / \mathrm{mL}$ should be within a reasonable viremia expected in a human host and represents a titer that can adequately infect another competent vector species.

The present study was meant to act as a pilot study for the evaluation of North American vectors for OROV, and the authors acknowledge limitations of the study design and utility. A major limitation is the age of the three colonies used for the infection assays. These assays utilized colonies that were available at the time of the study and the results should be interpreted as pilot data that can be used to guide future studies using younger colonies or low-generation field collected populations. However, based on the extremely low infection rates and the lack of evidence for dissemination or transmission, future studies with field populations of $C x$. tarsalis are likely not warranted for OROV. The slightly higher competence of $C x$. quinquefasciatus and its status as a confirmed vector in South America suggests this species would benefit from further studies. The high levels of infection and dissemination and moderate levels of transmission potential observed with C. sonorensis indicate that further studies with field populations are needed. Furthermore, it is unclear whether the use of two different blood sources (goose for both Culex species and calf for $C$. sonorensis) could have impacted the outcomes of these trials. The decision to use different blood sources was intended to increase blood feeding rates since each colony has been reared on their respective blood source over a long period. Future studies should endeavor to use more comparable blood sources when possible to eliminate this concern.

Another limitation of this study was the limited breadth of species evaluated. While the present study evaluated the vector competence of two different families of biting Diptera (Culicidae: Culex; and Ceratopogonidae: Culicoides), the known Culicidae vector breadth for OROV is much broader. Species such as Aedes serratus and Ae. scapularis (Rondani), Psorophora ferox (Humboldt), and Cq. venezuelensis have been implicated in the spread of OROV in South America [51]. For this study, $C x$. quinquefasciatus and $C x$. tarsalis were used because of accessibility of colony specimens and because of their significant role as arboviral vectors in North America. Additional studies will be needed to evaluate other common North American vector species, including species for which South American populations have been implicated. Furthermore, due to the role that avian migrations along flyways could potentially play, evaluating the vector competence of North American vectors that are known to feed on birds, such as Culex pipiens $\mathrm{L}$. and Culex restuans Theobald [52], Culiseta melanura (Coquillett) [53], and Coquillettidia perturbans (Walker) [54], is especially warranted to determine the threat that flyway-mediated introduction poses.

The present study demonstrates different vector competence levels of three North American vectors for OROV, with $\mathrm{C}$. sonorensis exhibiting the greatest competence. Nu- 
merous Culicoides species are present in North America [30], some of which are significant pests of humans such as the saltmarsh species Culicoides furens Poey. Although difficult to colonize, efforts should be made to evaluate the competence of other North American Culicoides species for OROV. Many North American Culicoides species are poorly studied, with numerous knowledge gaps pertaining to their ecology and control [23]. In the event of a Culicoides-driven OROV outbreak, control options to prevent widescale spread are limited and should be the focus of additional studies.

Supplementary Materials: The following are available online at https: / / www.mdpi.com/1999-491 5/13/2/226/s1, Supplementary File S1: Experimental Data.

Author Contributions: Conceptualization, B.L.M., C.R.C., and J.L.K.; Methodology, B.L.M. and J.L.K.; Formal Analysis: B.L.M.; Investigation: B.L.M. and J.L.K.; Resources: C.R.C. and J.L.K.; Data Curation: B.L.M.; Writing-Original Draft Preparation, B.L.M.; Writing—Review \& Editing: C.R.C. and J.L.K.; Visualization: B.L.M.; Supervision: C.R.C. and J.L.K. All authors have read and agreed to the published version of the manuscript.

Funding: This research received no external funding.

Institutional Review Board Statement: Not applicable.

Informed Consent Statement: Not applicable.

Data Availability Statement: Data are available as Supplemental File S1: Experimental Data.

Acknowledgments: The authors would like to thank Christie Mayo and Molly Carpenter at Colorado State University for their assistance with receiving Culicoides sonorensis from the USDA as well as William Yarnell and Dustin Swanson at the USDA Arthropod-Borne Animal Diseases Research Unit for rearing, preparing, and sending the midges. The authors also want to acknowledge Sean Masters and the animal care staff at the CDC for rearing the Culex used for these studies and Jason Velez for propagating cell lines and preparing plates for assays. Financial support for this project was provided internally by the CDC Division of Vector-Borne Diseases Arboviral Diseases Branch Ecology and Entomology Team and B.L. McGregor's postdoctoral fellowship funding was provided by the Oak Ridge Institute for Science and Education. Mention of trade names or commercial products in this publication is solely for the purpose of providing specific information and does not imply recommendation or endorsement by the CDC or the US Department of Agriculture. The conclusions of this report are those of the authors and do not necessarily represent the views of the USDA. USDA is an equal opportunity provider and employer.

Conflicts of Interest: The authors declare no conflict of interest.

\section{References}

1. Travassos da Rosa, J.F.; Marciel de Souza, W.; Pinheiro, F.P.; Figueiredo, M.L.; Cardoso, J.F.; Acrani, G.O.; Nunes, M.R.T. Oropouche virus: Clinical, epidemiological, and molecular aspects of a neglected Orthobunyavirus. Am. J. Trop. Med. Hyg. 2017, 96, 1019-1030.

2. $\quad$ Pinheiro, F.P.; Travassos da Rosa, A.P.A.; Travassos da Rosa, J.F.S.; Ishak, R.; Freitas, R.B.; Gomes, M.L.C.; LeDuc, J.W.; Oliva, O.F.; Oropouche Virus, I. A review of clinical, epidemiological, and ecological findings. Am. J. Trop. Med. Hyg. 1981, 30, 149-160. [CrossRef] [PubMed]

3. Mourão, M.P.G.; Bastos, M.S.; Gimaque, J.B.L.; Mota, B.R.; Souza, G.S.; Grimmer, G.H.N.; Galusso, E.S.; Arruda, E.; Figueiredo, L.T.M. Oropouche fever outbreak, Manaus, Brazil, 2007-2008. Emerg Infect. Dis. 2009, 15, 2063-2064. [CrossRef] [PubMed]

4. Tesh, R.B. The emerging epidemiology of Venezuelan hemorrhagic fever and Oropouche fever in tropical South America. Ann. N. Y. Acad. Sci. 1994, 740, 129-137. [CrossRef] [PubMed]

5. Baisley, K.J.; Watts, D.M.; Munstermann, L.E.; Wilson, M.L. Epidemiology of endemic Oropouche virus transmission in upper Amazonian Peru. Am. J. Trop. Med. Hyg. 2001, 59, 710-716. [CrossRef] [PubMed]

6. Romero-Alvarez, D.; Escobar, L.E. Oropouche fever, an emergent disease from the Americas. Microbes Infect. 2018, 20, 135-146. [CrossRef] [PubMed]

7. Wise, E.L.; Pullan, S.T.; Márquez, S.; Paz, V.; Mosquera, J.D.; Zapata, S.; Jackson, S.K.; Fejer, G.; Trueba, G.; Logue, C.H. Isolation of Oropouche virus from febrile patient, Ecuador. Emerg Infect. Dis. 2018, 24, 935-937. [CrossRef] [PubMed]

8. LeDuc, J.W.; Hoch, A.L.; Pinheiro, F.P.; Travassos da Rosa, A.P.A. Epidemic Oropouche virus disease in Northern Brazil. Bull. Pan Am. Health Organ. 1981, 15, 97-103. [PubMed] 
9. $\quad$ Pinheiro, F.P.; Hoch, A.L.; Gomes, M.L.; Roberts, D.R. Oropouche virus IV. Laboratory transmission by Culicoides paraensis. Am. J. Trop. Med. Hyg. 1980, 30, 172-176. [CrossRef]

10. Pinheiro, F.P.; Travassos da Rosa, A.P.A.; Travassos da Rosa, J.F.; Bensabath, G. An outbreak of Oropouche virus disease in the vicinity of Santarem, Para, Brazil. Tropenmed. Parasit. 1976, 27, 213-223.

11. Owen, J.; Moore, F.; Panella, N.; Edwards, E.; Bru, R.; Hughes, M.; Komar, N. Migrating birds as dispersal vehicles for West Nile virus. EcoHealth 2006, 3, 79. [CrossRef]

12. Smith, R.P.; Rand, P.W.; Lacombe, E.H.; Morris, S.R.; Holmes, D.W.; Caporale, D.A. Role of bird migration in the long-distance dispersal of Ixodes dammini, the vector of Lyme disease. J. Infect. Dis. 1996, 174, 221-224. [CrossRef] [PubMed]

13. Elfving, K.; Olsen, B.; Bergström, S.; Waldenström, J.; Lundkvist, Å.; Mejlon, H.; Nilsson, K. Dissemination of spotted fever Rickettsia agents in Europe by migrating birds. PLoS ONE 2010, 5, e8572. [CrossRef] [PubMed]

14. Bingham, A.M.; Burkett-Cadena, N.D.; Hassan, H.K.; McClure, C.J.W.; Unnasch, T.R. Field investigations of winter transmission of Eastern Equine Encephalitis virus in Florida. Am. J. Trop. Med. Hyg. 2014, 91, 685-693. [CrossRef]

15. Calisher, C.H.; Maness, K.S.C.; Lord, R.D.; Coleman, P.H. Identification of two South American strains of Eastern Equine Encephalomyelitis virus from migrant birds captured on the Mississippi Delta. Am. J. Epidem. 1971, 94, 172-178. [CrossRef]

16. Likos, A.; Griffin, I.; Bingham, A.M.; Stanek, D.; Fischer, M.; White, S.; Hamilton, J.; Eisenstein, L.; Atrubin, D.; Mulay, P.; et al. Local mosquito-borne transmission of Zika virus-Miami-Dade and Broward counties, Florida, June-August 2016. MMWR 2016, 65, 1032-1038. [CrossRef]

17. Tsetsarkin, K.A.; Vanlandingham, D.L.; McGee, C.E.; Higgs, S. A single mutation in Chikungunya virus affects vector specificity and epidemic potential. PLoS Path. 2007, 3, e201. [CrossRef]

18. Navarro, J.C.; Giambalyo, D.; Hernandez, R.; Auguste, A.J.; Tesh, R.B.; Weaver, S.C.; Montañez, H.; Liria, J.; Lima, A.; Travassos da Rosa, J.F.S.; et al. Isolation of Madre de Dios virus (Orthobunyavirus; Bunyaviridae), an Oropouche Virus species reassortant, from a monkey in Venezuela. Am. J. Trop. Med. Hyg. 2016, 95, 328-338. [CrossRef]

19. Aguilar, P.V.; Barrett, A.D.; Saeed, M.F.; Watts, D.M.; Russell, K.; Guevara, C.; Ampuero, J.S.; Suarez, L.; Cespedes, M.; Montgomery, J.M.; et al. Iquitos virus: A novel reassortant Orthobunyavirus associated with human illness in Peru. PLoS Neg. Trop. Dis. 2011, 5, e1315. [CrossRef]

20. Wilson, A.L.; Courtenay, O.; Kelly-Hope, L.A.; Scott, T.W.; Takken, W.; Torr, S.J.; Lindsay, S.W. The importance of vector control for the control and elimination of vector-borne diseases. PLoS Neg. Trop. Dis. 2020, 14, e0007831. [CrossRef]

21. Rosenberg, R.; Lindsey, N.P.; Fischer, M.; Gregory, C.J.; Hinckley, A.F.; Mead, P.S. Paz-Bailey, G.; Waterman, S.H.; Drexler, N.A.; Kersh, G.J.; et al. Vital Signs: Trends in reported vectorborne disease cases-United States and territories, 2004-2016. MMWR 2018, 67, 496-501.

22. Petersen, L.R.; Beard, C.B.; Visser, S.N. Combatting the increasing threat of vector-borne disease in the United States with a national vector-borne disease prevention and control system. Am. J. Trop. Med. Hyg. 2019, 100, 242-245. [CrossRef]

23. Pfannenstiel, R.S.; Mullens, B.A.; Ruder, M.G.; Zurek, L.; Cohnstaedt, L.W.; Nayduch, D. Management of North American Culicoides biting midges: Current knowledge and research needs. Vector-Borne Zoonotic Dis. 2015, 15, 374-384. [CrossRef]

24. Anderson, S.L.; Richards, S.L.; Smartt, C.T. A simple method for determining arbovirus transmission in mosquitoes. J. Am. Mosq. Control Assoc. 2010, 26, 108-111. [CrossRef]

25. Richards, S.L.; Lord, C.C.; Pesko, K.; Tabachnick, W.J. Environmental and biological factors influencing Culex pipiens quinquefasciatus Say (Diptera: Culicidae) vector competence for Saint Louis encephalitis virus. Am. J. Trop. Med. Hyg. 2009, 81, $264-272$. [CrossRef]

26. Alto, B.W.; Wiggins, K.; Eastmond, B.; Velez, D.; Lounibos, L.P.; Lord, C.C. Transmission risk of two chikungunya lineages by invasive mosquito vectors from Florida and the Dominican Republic. PLoS Neg. Trop. Dis. 2017, 11, e0005724. [CrossRef]

27. R Core Team. R: A Language and Environment for Statistical Computing; R Foundation for Statistical Computing: Vienna, Austria, 2019.

28. Darsie, R.F., Jr.; Ward, R.A. Identification and Geographical Distribution of the Mosquitoes of North America, North of Mexico; University Press of Florida: Gainesville, FL, USA, 2005; pp. 300-303.

29. Burkett-Cadena, N.D. Mosquitoes of the Southeastern United States; The University of Alabama Press: Tuscaloosa, AL, USA, 2013; pp. 141-147.

30. Borkent, A.; Grogan, W.L., Jr. Catalog of the New World Biting Midges North of Mexico. Zootaxa 2009, 2273, 1-48. [CrossRef]

31. Jewiss-Gaines, A.; Barelli, L.; Hunter, F.F. First records of Culicoides sonorensis (Diptera: Ceratopogonidae), a known vector of bluetongue virus, in Southern Ontario. J. Med. Entomol. 2017, 54, 757-762.

32. Huerta, H.; Castrejón, A.M.R.; Grogan, W.L., Jr.; Ibáñez-Bernal, S. Culicoides (Monoculicoides) variipennis complex. In New records of biting midges of the genus Culicoides Latreille from Mexico (Diptera: Ceratopogonidae). Insecta Mundi 2012, 0211, 12-14.

33. Price, D.A.; Hardy, W.T. Isolation of the bluetongue virus from Texas sheep-Culicoides shown to be a vector. J. Am. Vet. Med. Assoc. 1954, 124, 255-258.

34. Foster, N.M.; Breckon, R.D.; Luedke, A.J.; Jones, R.H. Transmission of two strains of epizootic hemorrhagic disease virus in deer by Culicoides variipennis. J. Wild Dis. 1977, 13, 9-16. [CrossRef] [PubMed]

35. Veronesi, E.; Henstock, M.; Gubbins, S.; Batten, C.; Manley, R.; Barber, J.; Hoffmann, B.; Beer, M.; Attoui, H.; Mertens, P.P.C.; et al. Implicating Culicoides biting midges as vectors of Schmallenberg virus using semi-quantitative RT-PCR. PLoS ONE 2013, 8, e57747. [CrossRef] [PubMed] 
36. Drolet, B.S.; Campbell, C.L.; Stuart, M.A.; Wilson, W.C. Vector competence of Culicoides sonorensis (Diptera: Ceratopogonidae) for vesicular stomatitis virus. J. Med. Entomol. 2005, 42, 409-418. [CrossRef] [PubMed]

37. Wellby, M.P.; Baylis, M.; Rawlings, P.; Mellor, P.S. Effect of temperature on survival and rate of virogenesis of African horse sickness virus in Culicoides variipennis sonorensis (Diptera: Ceratopogonidae) and its significance in relation to the epidemiology of the disease. Bull. Entomol. Res. 1996, 86, 715-720. [CrossRef]

38. Franz, A.W.E.; Kantor, A.M.; Passarelli, A.L.; Clem, R.J. Tissue barriers to arbovirus infection in mosquitoes. Viruses 2015, 7, 3741-3767. [CrossRef]

39. Langner, K.F.A.; Darpel, K.E.; Denison, E.; Drolet, B.S.; Leibold, W.; Mellor, P.S.; Mertens, P.P.C.; Nimtz, M.; Nimtz, G.W.I. Collection and analysis of salivary proteins from the biting midge Culicoides nebeculosus (Diptera: Ceratopogonidae). J. Med. Entomol. 2007, 44, 238-248. [CrossRef]

40. McGregor, B.L.; Erram, D.; Acevedo, C.; Alto, B.W.; Burkett-Cadena, N.D. Vector competence of Culicoides sonorensis (Diptera: Ceratopogonidae) for epizootic hemorrhagic disease virus serotype 2 strains from Canada and Florida. Viruses 2019, 11, 367. [CrossRef]

41. Smith, D.R.; Carrara, A.; Aguilar, P.V.; Weaver, S.C. Evaluation of methods to assess transmission potential of Venezuelan equine encephalitis virus by mosquitoes and estimation of mosquito salivary titers. Am. J. Trop. Med. Hyg. 2005, 73, 33-39. [CrossRef]

42. Kenney, J.L.; Adams, A.P.; Weaver, S.C. Transmission potential of two chimeric western equine encephalitis vaccine candidates in Culex tarsalis. Am. J. Trop. Med. Hyg. 2010, 82, 354-359. [CrossRef]

43. Roberts, D.R.; Pinheiro, F.P.; Hoch, A.L.; LeDuc, J.W.; Peterson, N.E.; Santos, M.A.V.; Western, K.A. Vectors and Natural Reservoirs of Oropouche Virus in The Amazon Region; Pan American Health Organization: Washington, DC, USA, 1977.

44. Hoch, A.L.; Pinheiro, F.P.; Roberts, D.R.; Gomes, M.L.C. Laboratory transmission of Oropouche virus by Culex quinquefasciatus. Bull. Pan Am. Health Organ. 1987, 21, 55-61.

45. Sakkas, H.; Bozidis, P.; Franks, A.; Papadopoulou, C. Oropouche fever: A review. Viruses 2018, 10, 175. [CrossRef] [PubMed]

46. Cardoso, B.F.; Serra, O.P.; Heinen, L.B.S.; Zuchi, N.; Souza, V.C.; Naveca, F.G.; Santos, M.A.M.; Slhessarenko, R.D. Detection of Oropouche virus segment $\mathrm{S}$ in patients and in Culex quinquefasciatus in the state of Mato Grosso, Brazil. Mem. Inst. Oswaldo Cruz 2015, 110, 745-754. [CrossRef] [PubMed]

47. David, M.R.; Ribeiro, G.S.; de Freitas, R.M. Bionomics of Culex quinquefasciatus within urban areas of Rio de Janeiro, Southeastern Brazil. Rev. Saúde Pública 2012, 46, 858-865. [CrossRef] [PubMed]

48. Kramer, L.D.; Ciota, A.T. Dissecting vectorial capacity for mosquito-borne viruses. Curr. Opin. Virol. 2015, 15, 112-118. [CrossRef]

49. Weaver, S.C.; Scott, T.W.; Lorenz, L.H.; Lerdthusnee, K.; Romoser, W.S. Togavirus-associated pathologic changes in the midgut of a natural mosquito vector. J. Virol. 1988, 62, 2083-2090. [CrossRef]

50. Pinheiro, F.P.; Travassos Da Rosa, A.P.A.; Gomes, M.L.C.; LeDuc, J.W.; Hoch, A.L. Transmission of Oropouche virus from man to hamster by the midge Culicoides paraensis. Science 1982, 215, 1251-1253. [CrossRef]

51. Anderson, C.R.; Spence, L.; Downs, W.G.; Aitken, T.H.G. Oropouche Virus: A new human disease agent from Trinidad, West Indies. Am. J. Trop. Med. Hyg. 1961, 10, 574-578. [CrossRef]

52. Molaei, G.; Andreadis, T.G.; Armstrong, P.M.; Anderson, J.F.; Vossbrinck, C.R. Host feeding patterns of Culex mosquitoes and West Nile virus transmission, Northeastern United States. Emerg. Infect. Dis. 2006, 12, 468-474. [CrossRef]

53. Molaei, G.; Andreadis, T.G. Identification of avian- and mammalian-derived bloodmeals in Aedes vexans and Culiseta melanura (Diptera: Culicidae) and its implication for West Nile virus transmission in Connecticut, U.S.A. J. Med. Entomol. 2006, 43, 1088-1093. [CrossRef]

54. Edman, J.D. Host-feeding patterns of Florida mosquitoes I. Aedes, Anopheles, Coquillettidia, Mansonia, and Psorophora. J. Med. Entomol. 1971, 8, 687-695. [CrossRef] 